BMJ Open

Sport \&

Exercise

Medicine

\title{
The anticipatory stress response to sport competition; a systematic review with meta-analysis of cortisol reactivity
}

\author{
Kjell N van Paridon, ${ }^{1}$ Matthew A Timmis, ${ }^{1}$ Charlotte $\mathrm{M}$ Nevison, ${ }^{2}$ Matt Bristow ${ }^{3}$
}

To cite: van Paridon KN, Timmis MA, Nevison CM, et al. The anticipatory stress response to sport competition; a systematic review with meta-analysis of cortisol reactivity. BMJ Open Sport Exerc Med 2017;: e000261. doi:10.1136/ bmjsem-2017-000261

- Additional material is published online only. To view please visit the journal online (http://dx.doi.org/ 10.1136/bmjsem-2017000261).

Accepted 4 August 2017

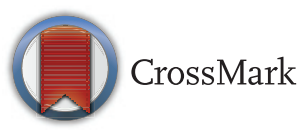

${ }^{1}$ Department of Sport and Exercise Sciences, Anglia Ruskin University Cambridge Centre for Sport and Exercise Sciences, Cambridge, UK 2Doctoral School, Anglia Ruskin University, Cambridge, UK

3Department of Psychology, Anglia Ruskin University, Cambridge, UK

\section{Correspondence to} Kjell N van Paridon; kjell.vanparidon@anglia.ac.uk

\section{ABSTRACT}

Objective Athletes anticipating sport competition regularly experience distinct emotional and physiological responses as a result of the expected psychosocial and physical stress. Specifically, cortisol, an indicator of hypothalamic-pituitary-adrenal axis activation, prepares the athlete for the psychological and physiological demands of competition. The objective of this meta-analysis is to analyse the magnitude of the anticipatory cortisol response in athletes preparing to participate in sport competition and to examine the influence of gender, level of competition and data collection time.

Design Systematic review with meta-analysis. Data sources Four electronic databases were searched to March 2017: PubMed, PsycINF0, SPORTDiscus and Scopus.

Eligibility criteria for selecting studies

(1) Athletes participating in real sport competition;

(2) salivary cortisol concentration collected before competition in addition to baseline sample(s);

(3) original research article published in English language.

Results Data from 25 studies provided 27 effect sizes. A significant anticipatory cortisol response of $g=0.85, p<0.001$ was identified. Males had a stronger trend for greater cortisol reactivity $(g=1.07)$ than females $(g=0.56, p=0.07)$. Females and athletes competing at international level did not demonstrate a significant anticipatory stress response. There were no significant differences between level of competition, type of sport or time of competition. Meta-regression indicated that the anticipatory cortisol response is greater when assessed closer to the start of competition $(\mathrm{Q}=6.85, \mathrm{p}=0.009)$.

\section{Summary/conclusion The anticipatory cortisol} response before sport competition reflects moderate cortisol reactivity that prepares athletes optimally for the demands of sport competition via the influence on cognitive processes and attentional control. However, both female athletes and international competitors did not demonstrate a significant anticipatory cortisol response, possibly due to differences in appraisal of the stress of sport competition.

\section{INTRODUCTION}

Athletes are often required to perform complex sporting skills in challenging and

\section{What are the new findings? \\ - Athletes anticipating sport competition demon- strate a moderate anticipatory cortisol response. \\ - Females and athletes competing at international level do not show a significant anticipatory cortisol response. \\ - The anticipatory cortisol response is greater when assessed closer to the start of sport competition.}

social evaluative environments. The subjective evaluation and appraisal of the athlete's ability to cope with the stressors of competition influence the development of negative emotional states. ${ }^{1}$ These negative emotions (eg, anxiety) are expected to trigger a biological stress response through activation of the sympathetic nervous system (SNS) and the hypothalamic-pituitary-adrenal (HPA) axis with the hormone cortisol as a marker of HPA-axis activation. ${ }^{2}$ However, both pathways are activated by distinctive psychological determinants. ${ }^{3}$ Challenge and effort are linked to SNS activation, whereas lack of control, harm and unpredictability outcome are more associated with HPA-axis activation. ${ }^{3-5}$ Due to the high level of agreement between serum and salivary cortisol concentrations and the ease of collection, studies more regularly use salivary cortisol as an indicator of HPA-axis activation over serum analysis. ${ }^{6}$ Based on the systematic analysis of laboratory studies of acute psychological stressors, Dickerson and Kemeny ${ }^{4}$ identified that cortisol is released under motivated, goal-relevant performance tasks during social-evaluative conditions. As these psychosocial factors resemble the psychological stressors of competitive sport, it is of interest to systematically examine whether participation in sport competition activates the HPA-axis. Craft $e t a l^{7}$ identified via a meta-analysis the presence of an emotional response (eg, cognitive and 
somatic anxiety) to anticipating sport competition. In addition, Hayes et $a l^{8}$ systematically examined the physiological effects of sport competition on the cortisol response and concluded that an increase in cortisol after sport competition was influenced by the timing of precompetition sampling and in particular the suggested presence of an anticipatory stress response.

A strong anticipatory rise in cortisol has been identified in anticipating participation in extreme sports ${ }^{9} 10$ as well as in social-evaluative laboratory stressors. ${ }^{4}$ An anticipatory increase in cortisol before sport competition is important to prepare for the psychological and physiological demands and is suggested to affect sport performance through its influence on cognitive processes (eg, prefrontal cortex-amygdala activation and deactivation ${ }^{11}{ }^{12}$ ). There is evidence that a moderate increase in cortisol is associated with reduced reaction time to identify task relevant stimuli and increased inhibition of aversive stimuli (eg, pictures of fearful faces or violent scenes) in comparison to low and high levels of cortisol secretion, which could facilitate sport performance. ${ }^{13}$ In contrast, high levels of cortisol are associated with a reduction in inhibition of task irrelevant stimuli, suggesting a debilitative effect on sport competition. ${ }^{14}$ Thus, moderate levels of cortisol might positively influence performance compared with low and high levels supporting the presence of an inverted U-relationship between cortisol and performance.

Variety in HPA-axis activation and cortisol reactivity is influenced by factors such as genetic predisposition as well as determinants such as gender, age and habituation. $^{2}{ }^{15}$ Kirschbaum et $a l^{16}$ identified that males demonstrated increased levels of salivary cortisol concentration in anticipation of participating in a social stress task, but this anticipatory stress response was absent in females. In contrast, van Stegeren $e t a l^{17}$ did not identify gender differences in cortisol response. It is relevant to note that the gender differences in HPA-axis activity to social stress tasks are still unclear due to confounding effects of factors such as age, contraceptive use and predominantly due to differences in the appraisal of psychosocial stressors used in stress protocols. ${ }^{18}$ Gender differences in HPAaxis activity have also been the primary aim of studies in the sport domain. Kivlighan et $a l^{19}$ identified no gender differences in cortisol concentration in the anticipation phase of competition. Salvador ${ }^{20}$ concluded that the anticipatory cortisol response to sport competition is often absent in women. Therefore, an investigation into HPA-axis activity in anticipation to sport competition should consider the moderation effects of gender.

Where the effects of gender differences on HPA-activation is inconclusive, an even more complex interaction takes place with the effects of age, experience and habituation to stressful events. Experienced athletes have had more exposure to stressful competition. It is suggested that repeated exposure to stressful events reduces the HPA-axis activation in social stress tasks $^{21}$ as well as in extreme sports (eg, sky-diving). ${ }^{22}$ However, the peak cortisol concentration before skydiving is not different between experienced versus less experienced sky-divers ${ }^{9}$ where the pattern of cortisol reactivity (eg, quick rise and reduction) is distinct. ${ }^{10}$ Therefore, it is anticipated that age and experience might play a greater role in the pattern of cortisol reactivity than in the magnitude of the cortisol response.

One of the key challenges in investigating the psychosocial effects of sport competition on the cortisol response is separating cortisol secretion due to emotional stress or due to physiological demands of the exercise. Exercise intensity influences blood glucose levels and declining blood glucose levels elicit the hypothalamus to secrete the corticotrophin releasing hormone (CRH). CRH triggers the release of the adrenocorticotropic hormone which activates the adrenal cortex to release cortisol. ${ }^{23}$ The release of cortisol in this mechanism supports homeostasis of blood glucose levels by stimulating gluconeogenesis from amino acids and mobilising free fatty acids from adipose tissue. ${ }^{23}$ Cortisol secretion with the aim of mobilising energy sources is therefore independent from experiencing psychosocial stressors and is mainly a function of exercise intensity. Indeed, Jacks et $a l^{24}$ identified that blood glucose significantly decreased while salivary cortisol significantly increased after 59 min of high intensity exercise in comparison to rest and low-intensity exercise. This finding is supported by the conclusion from Kudielka et $a l^{15}$ that both maximal physical exercise and sustained exercise above $70 \%$ of the VO2max will significantly increase cortisol concentrations compared with moderate exercise intensities. Therefore, to examine psychosocial stress and cortisol reactivity in sport competition, it is important to investigate the anticipatory stress response in contrast to exercise induced changes. If precompetition cortisol has a possible influence on sport performance, it is of interest to examine the magnitude of this anticipatory cortisol response. By means of a meta-analysis, it is possible to aggregate the results of other studies and to examine the influence of moderating variables on the anticipatory cortisol response before competition.

\section{AIM AND HYPOTHESIS}

The aim of this meta-analysis is to aggregate the findings of studies on the effects of anticipating competing in real sport competitions on the salivary cortisol concentration of athletes. We hypothesise that the anticipation to compete in competitive sports results in an increase in salivary cortisol from baseline levels. Laboratory studies ${ }^{25}$ have identified that the anticipatory cortisol response is higher when assessed closer to exposure to the stressor. We hypothesise that the anticipatory salivary cortisol response is higher when 
assessed closer to the start time of sport competition. In addition, the aim is to examine the effects of the moderator variables gender, experience and competitive level on the anticipatory salivary cortisol response.

\section{METHODS}

\section{Search strategy}

The electronic databases PubMed, PsycINFO, SPORTDiscus and Scopus were searched separately on 26 October 2015 with an updated search on 1 March 2017. To obtain studies on the anticipatory cortisol response to competitions, we used the following combination of key words in our search strategy 'hydrocortisone' OR 'cortisol' AND 'anxiety' OR 'stress' OR 'arousal' AND 'sports' OR 'sport' OR 'athlet*' OR 'match' OR 'competition' (see online supplementary file 1). No cut-off publication date was used and the reference lists of included studies were examined for additional studies that could meet the inclusion criteria. The search strategy and reporting of the meta-analysis was conducted according to the PRISMA Statement. ${ }^{26}$

\section{Inclusion/exclusion criteria}

Initially, the title and abstract of the identified studies were examined; studies were included when they met the following criteria: (1) a study must include participants who were competing in a real sport competition in contrast to an experimentally created sport competition; (2) free (unbound) cortisol concentrations were determined from saliva samples; (3) saliva samples were collected before the sport competition; (4) timematched resting or baseline samples were collected on a non-competition day. Studies were included when published as a full-text manuscript in a peer-reviewed journal and written in English. Whenever there was the suggestion from the title and abstract that a study could meet the inclusion criteria, the full text of the study was examined. Studies were excluded when (1) baseline samples were not collected, collected on the day of the sport competition or not time-matched; (2) saliva flow was stimulated via a reagent (eg, citric acid); (3) performing arts or extreme sports (eg, sky-diving, scuba diving, rock climbing) were used as manipulation. The process of confirming studies for inclusion and exclusion was performed independently by two reviewers ( $\mathrm{KNvP}$ and $\mathrm{JL}$, research assistant) at study and study outcome level. Disagreements between reviewers were resolved via a discussion of eligibility criteria and study information to reach consensus. To reduce the chances of bias within the meta-analysis, studies were examined when there was the suggestion that cortisol responses were derived from the same sample of participants but reported in multiple studies $(n=2)$. When this occurred, the publication was chosen that included (1) the largest amount of information (eg, timing, mean cortisol concentration) or (2) the highest number of participants.

\section{Data extraction}

Full text manuscripts were examined and the following information was extracted and coded.

\section{Participant characteristics}

Number of participants, gender, years of playing experience, level of competition, team or individual sport and type of sport.

\section{Cortisol}

Mean salivary cortisol concentration and SD before competition and the mean salivary cortisol concentration and SD from the rest samples.

\section{Cortisol collection}

Exact time of saliva collection, exact time of competition, before or after midday saliva collection, saliva collection method, saliva cortisol assay method.

For effect size estimates of individual studies, the standardised mean difference (Cohen's d) was used based on the rest and precompetition cortisol concentration divided by the population pooled SD. The effect sizes were calculated with the formula:

$$
d=\frac{\left(M_{\text {cortcomp }}-M_{\text {cortrest }}\right)}{\sqrt{\left.S D_{\text {cortcomp }}^{2}+S D_{\text {cortrest }}^{2}\right) / 2}}
$$

When the concentration of cortisol in saliva and/or the SD were not fully presented numerically within the study, the following procedure was used to derive the effect size. (1) When data were presented in figures numerical information was derived from digitising figures with figure digitising software (Plot Digitizer V.2.6.8, http://plotdigitizer.sourceforge.net). ${ }^{27} \quad 28$ (2) When this was not possible, inferential statistical information was used to calculate the effect size.

(3) When 1 and 2 were not possible, the authors were contacted and asked for the relevant information.

If studies reported multiple relevant effect sizes (eg, gender differences), separate effect sizes were extracted. When repeated measures or games were presented, an average of the precompetition and/or baseline cortisol concentration and variation were used to derive one effect size. For example, Carré et $a l^{29}$ and Cunniffe et $a l^{30}$ reported the cortisol response in the same participants in home and away games; as game location was not considered a moderating variable, the average from the two competitions was used. In other instances, where comparisons were made between winners and losers, ${ }^{31}$ an average of the cortisol concentrations and variation was created to derive one effect size. When cortisol was assessed on multiple time points from the same participants, the saliva collection time point closest to the start of the competition was used. 


\section{Statistical analysis}

A random effects meta-analysis was used for all analysis as heterogeneity across studies was expected. ${ }^{32}$ All analyses were conducted in the Comprehensive Metaanalysis programme (CMA V.3.3.070). The calculated standardised mean effect sizes were corrected for small sample bias with the Hedge $\mathrm{J}$ correction with the formula:

$$
g=d *\left(1-\left(\frac{3}{4 * d f-1}\right)\right)
$$

The resulting Hedges' g effect sizes were used in the analysis. Initially, $\mathrm{Z}$ statistics were used to examine whether the overall effect was significantly different from no effect. The $\mathrm{Q}$-statistic and $\mathrm{I}^{2}$ measure were used to examine the heterogeneity within the sample of effects sizes. Based on a significant $Q$ statistic and an $\mathrm{I}^{2}$ measure of above $75 \%$, heterogeneity was assumed and subsequently the effects of moderating variables were analysed. The influence of moderating variables on the cortisol response was assessed via subgroup analysis of variance. To assess the association between continues variables (eg, saliva collection time) and salivary cortisol, meta-regression was conducted. ${ }^{32} \mathrm{~A} p$ value of 0.05 was used in all analyses to indicate significant differences.

\section{RESULTS}

\section{Study selection}

From the identification process, the titles and abstracts of 1593 studies were screened (figure 1). Within screening, studies were predominantly excluded due to the focus on health, immune

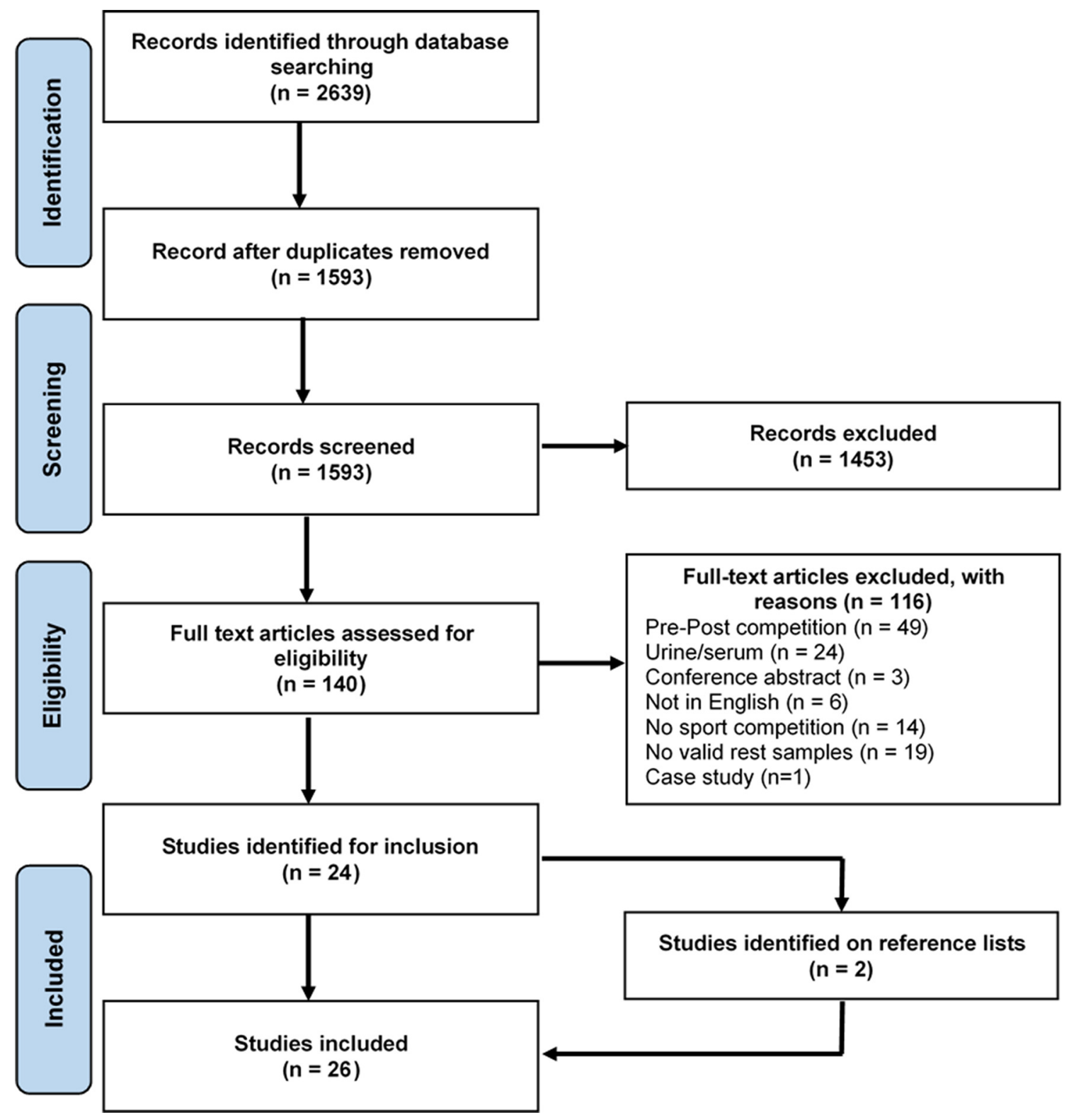

Figure 1 Flow chart of search strategy. 
Table 1 Descriptive characteristics of studies included in the analysis

\begin{tabular}{|c|c|c|c|c|c|c|c|}
\hline \multirow[b]{2}{*}{ Study } & \multicolumn{7}{|c|}{ Study characteristics } \\
\hline & $\mathbf{N}$ & Gender & Age & Type & Level & Time of day & Collection time \\
\hline Alix-Sy et $a l^{49}$ & 18 & $\mathrm{~m}$ & 24.6 & $\mathrm{~T}$ & NAT & PM & 90 \\
\hline Balthazar et al ${ }^{48}$ & 8 & $\mathrm{~m}$ & 27.8 & I & NAT & AM & 0 \\
\hline Bateup et $a /^{33}$ & 17 & $f$ & 20 & $T$ & NAT & PM & 15 \\
\hline Booth et al ${ }^{50}$ & 6 & $\mathrm{~m}$ & 19 & I & NAT & PM & 15 \\
\hline Carré et $a l^{29}$ & 14 & $\mathrm{~m}$ & 18.2 & $T$ & NAT & PM & 45 \\
\hline Coelho et $a l^{51}$ & 17 & $\mathrm{~m}$ & 23.6 & I & INT & PM & 30 \\
\hline Harris et $\left.a\right|^{52}$ & 8 & $\mathrm{~m}$ & 35.1 & 1 & REG & AM & 0 \\
\hline Cunniffe et $\left.a\right|^{30}$ & 15 & $\mathrm{~m}$ & 26.2 & $\mathrm{~T}$ & INT & PM & 90 \\
\hline Díaz et $a l^{53}$ & 11 & $\mathrm{~m}$ & 21.5 & 1 & NAT & PM & 120 \\
\hline Doan et al/7 & 8 & $\mathrm{~m}$ & 20.3 & I & NAT & AM & 45 \\
\hline \multicolumn{8}{|l|}{ Edwards et $a l^{34}$} \\
\hline Team & 15 & $f$ & - & $\mathrm{T}$ & REG & PM & 95 \\
\hline Individual & 13 & $\mathrm{f}$ & - & I & NAT & PM & 10 \\
\hline Elloumi et $a l^{54}$ & 20 & $\mathrm{~m}$ & 25.8 & $\mathrm{~T}$ & INT & PM & 180 \\
\hline Filaire et $\left.a\right|^{55}$ & 12 & $f$ & 12.5 & 1 & NAT & PM & 5 \\
\hline Filaire et $\left.a\right|^{31}$ & 18 & $\mathrm{~m}$ & 22.2 & I & REG & PM & 5 \\
\hline Haneishi et al ${ }^{56}$ & 10 & $f$ & 20.2 & $T$ & NAT & PM & 30 \\
\hline \multicolumn{8}{|l|}{ lellamo et al ${ }^{41}$} \\
\hline Male & 4 & $\mathrm{~m}$ & 26.7 & I & NAT & AM & 0 \\
\hline Female & 4 & $f$ & 26.7 & I & NAT & AM & 0 \\
\hline McKay et $a l^{57}$ & 15 & $\mathrm{~m}$ & 22.5 & 1 & NAT & - & 20 \\
\hline McLellan et $a^{58}$ & 17 & $\mathrm{~m}$ & 24.2 & $\mathrm{~T}$ & NAT & PM & 30 \\
\hline Moreira et $a l^{59}$ & 12 & $\mathrm{~m}$ & 19 & $T$ & NAT & PM & 30 \\
\hline Oliveira et $a l^{60}$ & 23 & $f$ & 24.2 & $\mathrm{~T}$ & NAT & PM & 30 \\
\hline Piacentini et $a l^{61}$ & 5 & $\mathrm{~m}$ & 47 & 1 & NAT & AM & 0 \\
\hline Robazza et al ${ }^{62}$ & 9 & $\mathrm{~m}$ & 29.1 & $\mathrm{~T}$ & NAT & PM & 0 \\
\hline Salvador et al ${ }^{63}$ & 17 & $\mathrm{~m}$ & 19.4 & 1 & REG & AM & 40 \\
\hline Sperlich et al ${ }^{64}$ & 17 & $\mathrm{~m}$ & 22 & I & NAT & - & 2 \\
\hline Yuan et $a l^{65}$ & 16 & $\operatorname{mix}$ & 15.4 & 1 & REG & AM & 45 \\
\hline
\end{tabular}

$\mathrm{n}$, number of participants in the study. Gender: $\mathrm{f}$, female athletes; $\mathrm{m}$, male athletes; mix, mixed gender population. Type: I, individual sport; $\mathrm{T}$, team sport. Level: INT, International; NAT, National; REG, Regional. Time of day: AM=Morning, PM=Afternoon. Collection time: Saliva collection time in minutes before start of the competition. Dashes indicate that data were not available.

functioning or overtraining. The full text of the remaining studies was examined for eligibility where 24 studies met the inclusion criteria. The reference lists of the identified 24 studies resulted in two more studies that were eligible for inclusion. ${ }^{33} 34$ Data of these 26 studies were extracted. We were not able to gather all the necessary data to include the results from one study, ${ }^{35}$ so this study was excluded. The analyses were conducted on 25 studies.

\section{Study characteristics}

An overview of the characteristics of the 25 included studies with 27 effect sizes and 348 participants is presented in table 1 . The average sample size $( \pm \mathrm{SD})$ was $13 \pm 5$ participants per study with an average participant age of $23.7 \pm 6.8$ years. The proportion of male athletes in the sample was $67 \%$. Female athletes accounted for $27 \%$ and two studies $(6 \%$ of the participant sample) used a mixed gender population. In total, 11 effect sizes with a total of 170 participants 
Study name

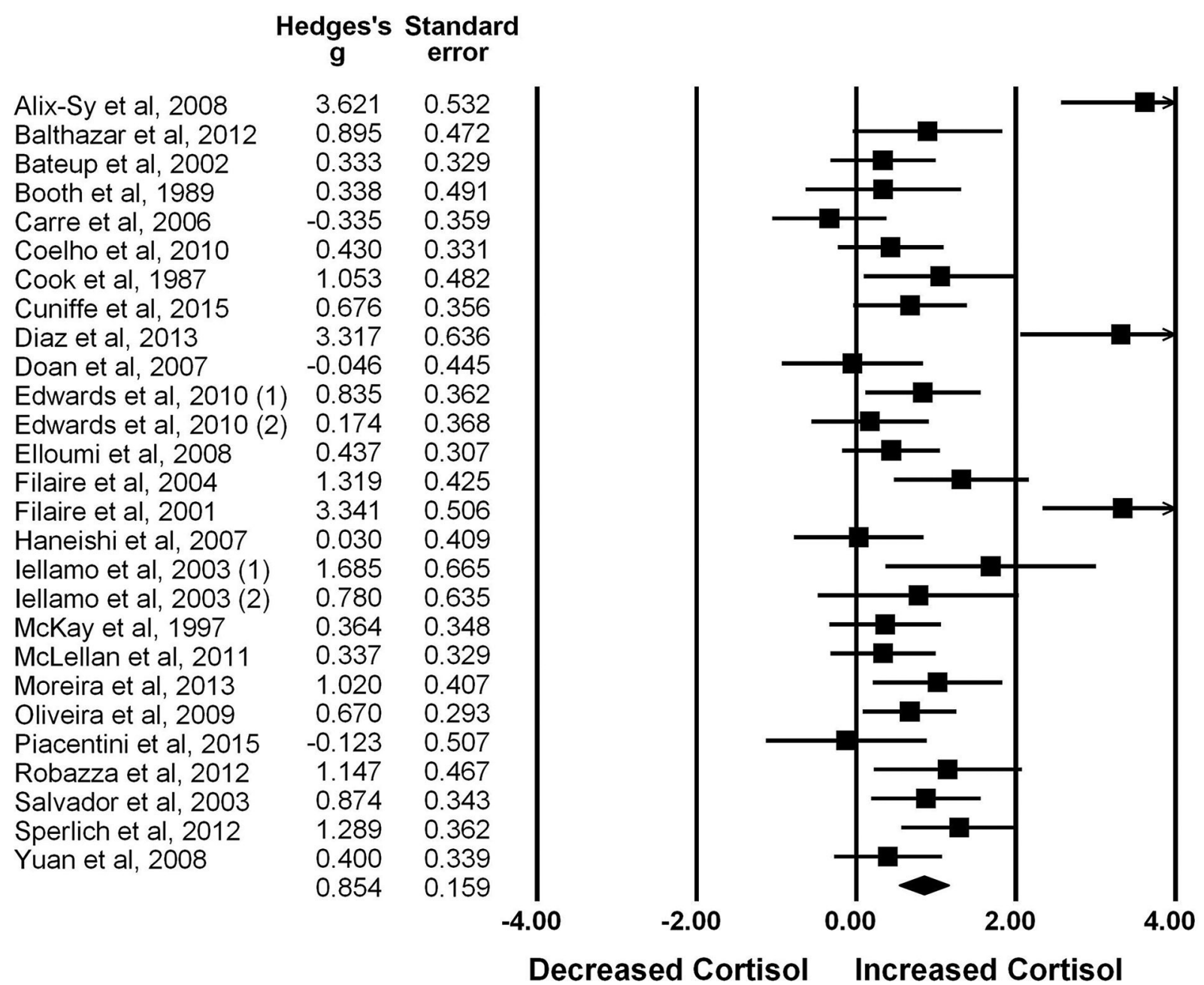

Figure 2 Forest plot of the included studies average effect sizes by weight.

came from studies using athletes from team sports where the other 16 used athletes from individual sports.

\section{Publication bias}

To assess bias towards including published studies with significant results over unpublished studies with nonsignificant results in the meta-analysis, Egger's test of funnel plot asymmetry was used to calculate the failsafe $\mathrm{N}$ in the overall cortisol response. Assessment of publication bias indicated a fail-safe $\mathrm{N}$ of 734 studies to reduce the overall effect to below $\mathrm{p}=0.05$.

The anticipatory cortisol response to competition

The random effects meta-analysis identified a large and significant cortisol response in athletes anticipating sport competition $(\mathrm{g}=0.85, \mathrm{SE}=0.16,95 \% \mathrm{CI}$ 0.54 to $1.17, \mathrm{Z}=5.38, \mathrm{p}<0.001$ ). Large heterogeneity was observed among studies $(\mathrm{Q}=108.38, \mathrm{p}<0.001)$ indicating variance in anticipatory cortisol response that could be explained by moderating variables (figure 2).

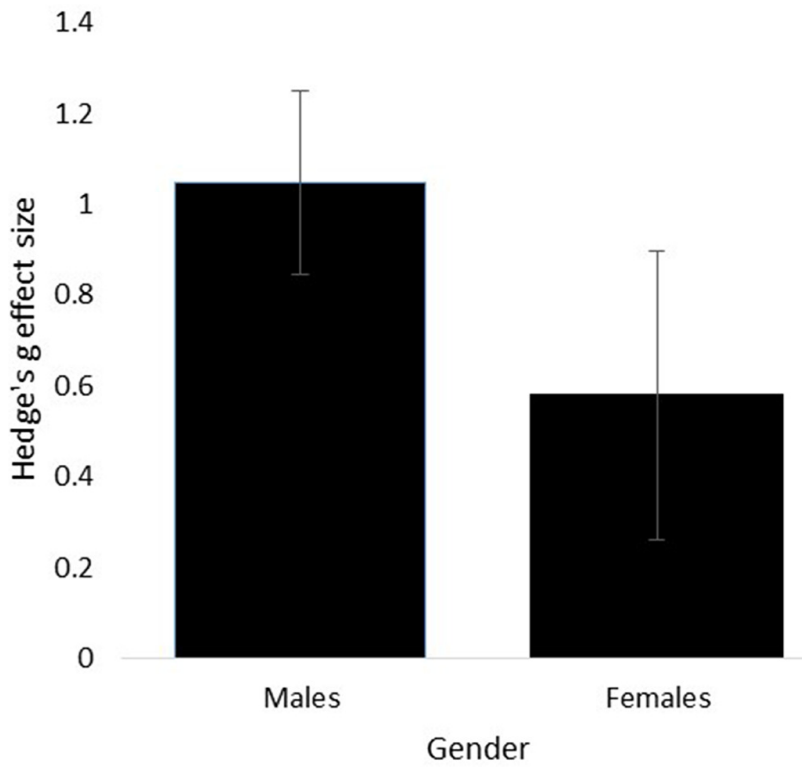

Figure 3 Hedge's g effect sizes of cortisol reactivity in male and females. 


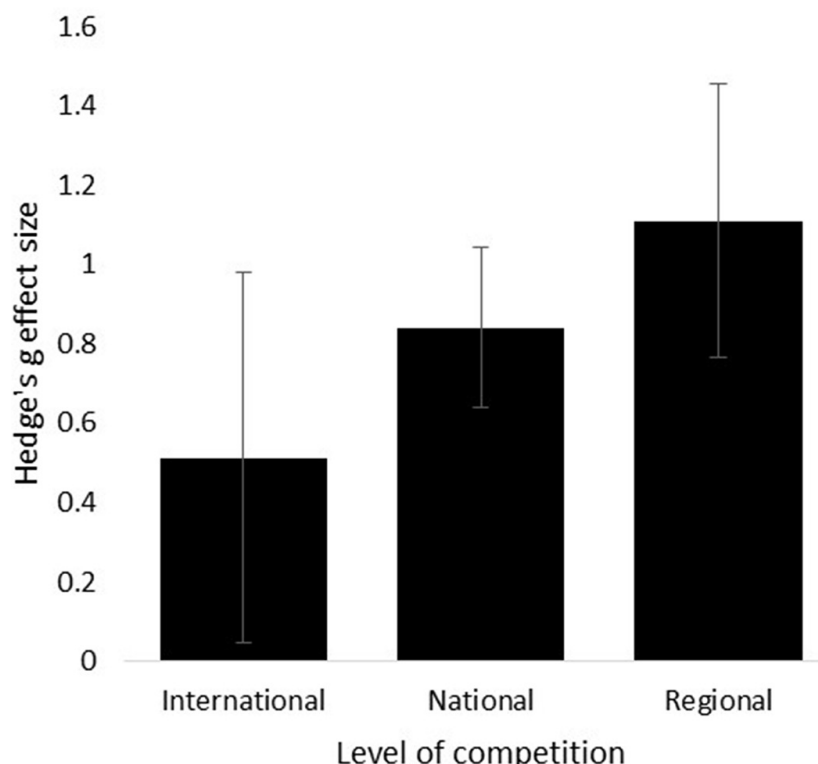

Figure 4 Hedge's g effect sizes of cortisol for international, national and regional athletes.

The effect of gender on the anticipatory cortisol response to competition

A significant anticipatory cortisol response was identified in the 19 studies with male athletes $(\mathrm{g}=1.05$, $\mathrm{SE}=0.20,95 \%$ CI 0.65 to $1.44, \mathrm{Z}=5.19, \mathrm{p}<0.001)$. In contrast, the anticipatory cortisol response of the seven studies with female athletes was not significantly different $(\mathrm{g}=0.58, \mathrm{SE}=0.32,95 \% \mathrm{CI}-0.042$ to 1.20 , $\mathrm{Z}=1.83, \mathrm{p}=0.07)$. There was no significant difference in the anticipatory cortisol response between males and females $(Q(1)=1.54, p=0.21)$ where the true differences between males and females fall in the range of -0.24 and 1.24 (figure 3 ).

\section{The effect of team and individual sport on the cortisol response}

A significant anticipatory cortisol response was identified in studies that used athletes who competed individually $(\mathrm{g}=0.94, \mathrm{SE}=0.21,95 \% \mathrm{CI} 0.53$ to 1.36 , $\mathrm{Z}=4.42, \mathrm{p}<0.001)$ as well as in athletes competing in team sports $(g=0.74, \mathrm{SE}=0.25,95 \%$ CI 0.26 to 1.22 , $\mathrm{Z}=3.02, \mathrm{p}=0.003)$. There was no significant difference between athletes of these two modes of sport $(Q(1)$ $=0.39, \mathrm{p}=0.53$ ).

\section{The effect of level of competition on the cortisol response}

A comparison between athletes competing at regional, national or international level identified that there was no significant difference between these types of athletes on the anticipatory cortisol response $(\mathrm{Q}(2)=1.03$, $\mathrm{p}=0.60$, figure 4$)$. Athletes competing at national level $(\mathrm{g}=0.84, \mathrm{SE}=0.20,95 \% \mathrm{CI} 0.44$ to $1.24, \mathrm{Z}=4.16$, $\mathrm{p}<0.001)$ and at regional level $(\mathrm{g}=1.11, \mathrm{SE}=0.35$, $95 \%$ CI 0.42 to $1.78, \mathrm{Z}=3.17, \mathrm{p}=0.002$ ) showed a significant anticipatory cortisol response in comparison to no response. However, athletes competing at international level did not demonstrate a significant anticipatory cortisol response $(\mathrm{g}=0.51, \quad \mathrm{SE}=0.47$, $95 \% \mathrm{CI}-0.40$ to $1.43, \mathrm{Z}=1.10, \mathrm{p}=0.23)$.

The effect of time of competition (am vs pm) on the cortisol response

To examine the influence of the circadian rhythm of cortisol on the anticipatory cortisol response, studies with sport competition in the morning and afternoon were compared. No significant difference in cortisol reactivity between morning and afternoon competition was identified $(Q(1)=0.59, \quad \mathrm{p}=0.44)$ where both morning $(\mathrm{g}=0.66, \mathrm{SE}=0.32,95 \% \mathrm{CI} 0.037$ to 1.28 , $\mathrm{Z}=2.08, \quad \mathrm{p}=0.04)$ and afternoon studies $(\mathrm{g}=0.95$, $\mathrm{SE}=0.20,95 \%$ CI 0.54 to $1.36, \mathrm{Z}=4.57, \mathrm{p}<0.001)$ showed a significant anticipatory cortisol response.

\section{Collection time before competition and cortisol response}

To test the effects of data collection time before competition on the cortisol response, a random effects regression analysis with Hedge's g effect sizes versus the data collection time point before competition was conducted. To create a homogenous sample, five effect sizes were excluded from this analysis, as these samples were all collected a minimum of 45 min later than the 22 included effect sizes (see table 1). All 22 effect sizes collected saliva samples up to $45 \mathrm{~min}$ before the start of the competition. The collection time of saliva samples before competition significantly related to the anticipatory cortisol response $(\mathrm{Q}(1)=6.85, \mathrm{p}=0.009)$. The negative slope of the regression line indicated a larger anticipatory cortisol response when samples are collected closer to start of the competition (see figure $5)$. In addition, goodness of fit was significantly different $\left(\mathrm{Q}(20)=46.16, \mathrm{p}<0.001, \mathrm{R}^{2}\right.$ of 0.29$)$, indicating that $29 \%$ of the variance in cortisol effect can be explained by saliva collection time.

\section{DISCUSSION}

The main aim of the meta-analysis was to identify whether the anticipation to participate in sport competition influences the salivary cortisol concentration. To examine this, the results of 25 studies that measured salivary cortisol before sport competition, in addition to a time-matched baseline sample on a control day were combined. Effect sizes were calculated based on the change in cortisol concentration from timematched baseline to before sport competition. The combined results identified the presence of a significant anticipatory cortisol response before competition $(g=0.85)$ where the anticipatory cortisol response is significantly greater when assessed closer to the start of competition. These findings further support the presence of anticipatory stress response in athletes before sport competition. However, we identified large 
heterogeneity between effect sizes from individual studies where our analysis of moderating variables (eg, gender, type of sport) could not fully explain this large heterogeneity.

Hanton $e t a l^{36}$ identified a significant increase in cognitive and somatic anxiety in the time leading up to competition. The findings of our meta-analysis support ${ }^{36}$ with the conclusion that there is also a significant increase in the biological stress response leading up to sport competition. The average anticipatory cortisol response of 0.85 corresponds to the cortisol response in laboratory based stress manipulations using the Trier Social Stress Test (TSST, $d=0.86^{4}$ ). However, the cortisol response before sport competition is lower than identified in extreme sports such as sky-diving $\left(\mathrm{d}=1.5^{22}\right)$. The positive effects of moderate cortisol concentrations on reaction time and inhibition of aversive stimuli are associated with moderate cortisol responses $(\mathrm{d}=1.0)$ reflecting a dosage of $5 \mathrm{mg}$ exogenous cortisol. ${ }^{13} 37$ In contrast, negative effects of cortisol through reduced inhibition of task irrelevant stimuli are related to large cortisol responses $(\mathrm{d}=1.4-$ $\mathrm{d}=3.0$ ) reflecting a dosage of $10-40 \mathrm{mg}$ exogenous cortisol. $^{14} 38$ Therefore, the identified anticipatory cortisol response of 0.85 before sport competition reflects moderate cortisol reactivity which prepares the athlete optimally for the psychological and physiological demands of competition.

\section{Gender differences}

Males had a significant anticipatory cortisol response but this was not identified in females. In addition, there was a strong indication that males experience a greater anticipatory cortisol response $(\mathrm{g}=1.05)$ than females before sport competition $(g=0.58, p=0.06$, figure 3). This finding confirms previous results of gender differences in cortisol reactivity after exposure to psychological stress. ${ }^{18}$ Males tend to have a significantly greater cortisol reactivity both in anticipation and response to the TSST than females. ${ }^{16} 39$ Our findings further support this, where the absence of the anticipatory cortisol response and strong trend for males to show greater cortisol reactivity than females can be related to gender differences in the interpretation of psychological stressors. Psychological stressors related to challenges tends to stimulate HPA-axis activity more in males, where females show greater HPA-axis reactivity in social rejection paradigms. ${ }^{40}$ The psychological stress associated with sport competition (eg, performance failure, achievement challenges) reflects this challenged state, explaining the higher anticipatory stress response in males. One study in the analysis included a comparison between male and female athletes. ${ }^{41}$ While a small sample size was used (three females and four males), a greater increase in anticipatory cortisol was observed in males (2.7-fold increase) compared with females (1.6-fold increase). The findings that males show stronger emotional responses (eg, cognitive-somatic anxiety) in anticipation to sport competition compared with females ${ }^{7} 42$ are further supported by the indication that males also demonstrate a stronger anticipatory cortisol response to sport competition.

\section{Team versus individual competition}

Within team sports athletes interact and share responsibility to achieve goals related to successful sport performance. This cooperation offers opportunities for social interactions between athletes in preparation to and during competition. This shared responsibility to the outcome and opportunities for social interaction reduces cognitive and somatic anxiety responses before sport competition in team sport athletes in comparison to individual athletes. ${ }^{73}$ In addition, providing verbal social support during psychosocial stress tasks reduces the cortisol response in comparison to not receiving this support. ${ }^{44}$ Therefore, we analysed whether athletes participating in team sports have a lower anticipatory cortisol response in comparison to individual athletes. Although our results indicate that both team $(g=0.74$, $\mathrm{p}=0.003)$ and individual athletes $(\mathrm{g}=0.94, \mathrm{p}<0.001)$ demonstrate a significant anticipatory cortisol response, there were no differences between the team and individual athletes. This finding might be affected by the large variation in individual cortisol reactivity, resulting in large SD of the included effect sizes. As previous studies identify differences in the emotional response between team and individual athletes, it is of interest to examine whether team and individual athletes differ in cortisol reactivity in experimental studies with a repeated measures design. For example, sports where athletes compete both individually and in pairs (eg, tennis, golf) could be used to examine whether social influences of team sports affect cortisol reactivity.

\section{Cortisol reactivity and level of competition}

Studies were categorised into regional, national or international level based on the characteristics of the athletes and/or the sport competition to assess whether level of competition affected cortisol reactivity. Where both regional $(\mathrm{g}=1.1, \mathrm{p}=0.002)$ and national level competitors $(\mathrm{g}=0.84, \mathrm{p}<0.001)$ showed a significant increase in cortisol, this was absent in the international level competitors $(g=0.51, p=0.23)$. The absence of a significant cortisol response in international athletes could be related to the timing of collection of saliva samples, where studies with international athletes collected samples longer before the start of competition (30-180 min before) compared with studies with national or regional athletes. No significant differences between the three subgroups of level of competition were identified $(p=0.60)$. The categorisation of studies into level of competition, and not on the years of experience at this competitive level, might have affected these results. For example, Mellalieu et $a l^{45}$ identified 
that the emotional response (eg, cognitive anxiety) before sport competition was significantly lower in more experienced athletes compared with less experience players. This finding is further supported by Kivlighan et $a l^{19}$ who identified that the anticipatory cortisol response in a created rowing competition was significantly lower in more experienced athletes compared with novices. The results of our analysis on the level of competition might be influenced by the level of experience of the athletes within the studies. As playing experience at the assessed competition level was not reported in the majority of studies, it was not possible to analyse whether playing experience might affect the anticipatory cortisol response.

\section{The effects of time of competition}

Salivary cortisol follows a circadian rhythm, where following awakening, an increase in cortisol is identified and during the day cortisol gradually decreases. ${ }^{46}$ The lowest levels of cortisol are typically reported during the evening. To assess whether competing at different times of the day would affect the anticipatory cortisol response, studies were separated into morning and afternoon. Seven studies assessed cortisol in the morning and 17 studies in the afternoon. Both morning $(\mathrm{g}=0.66, \mathrm{p}=0.04)$ and afternoon studies $(\mathrm{g}=0.95, \mathrm{p}<0.001)$ showed a significant anticipatory cortisol response. However, there was no indication that the anticipatory cortisol response was different between morning and afternoon studies $(p=0.44)$.
Dickerson and Kemeny ${ }^{4}$ identified that morning studies have a small cortisol response in comparison to larger effect sizes in afternoon studies. The identified difference by Dickerson and Kemeny ${ }^{4}$ of 0.32 resembles the difference of our analysis (0.29). The nonsignificant difference between morning and afternoon is possibly due to relative low number of effect sizes included in this analysis. Furthermore, the type of sport played was not controlled for. For example, different sports, played at different times of day were included in the analysis. Further research needs to consider whether the type of sport impacts cortisol measures. However, it is recommended that studies examining cortisol reactivity in sport recognise the influence of the awakening response. For example, it is likely that the cortisol awakening response influenced baseline or precompetition cortisol concentration in studies with early morning competition (eg, golf ${ }^{47}$ ).

\section{Cortisol reactivity and collection time}

The results from the regression analysis on the effect size of the anticipatory cortisol response and data collection time before sport competition identified that the anticipatory effect of cortisol is increased when samples are collected closer to the start of competition $(p=0.009$, figure 5). This finding further supports previous studies on the emotional response to sport competition. Hanton et $a l^{36}$ identified that cognitive and somatic anxiety significantly increased from 2 hours before competition to $30 \mathrm{~min}$ before

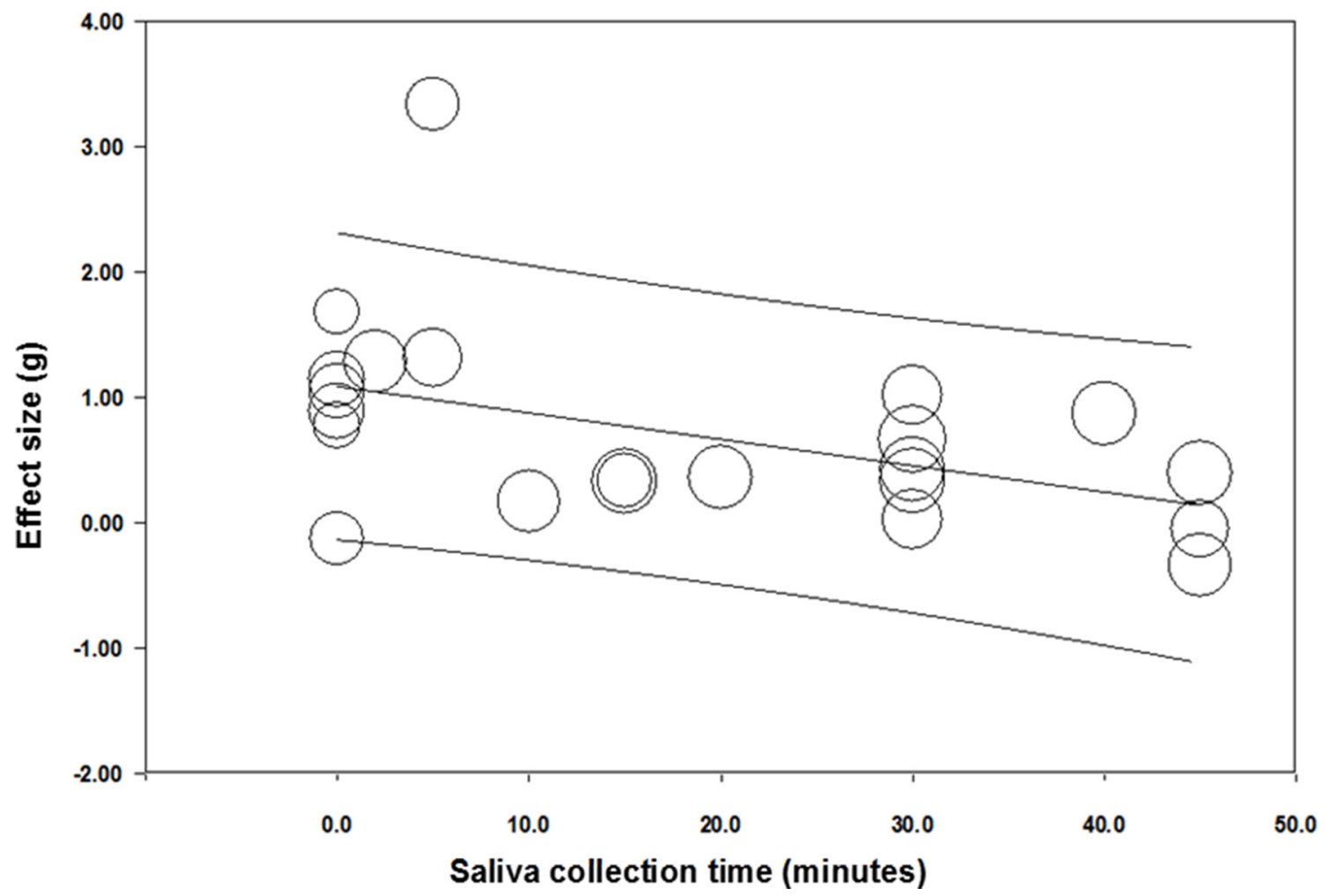

Figure 5 Hedge's g effect sizes of the cortisol response of competition against saliva data collection time before competition. Larger value on $\mathrm{Y}$ axis denotes that samples were collected a longer time from the start of competition. 
competition. Although studies on the cortisol response to laboratory psychosocial stressors tend to show an increase in cortisol in reaction to the application of the stressor, ${ }^{4}$ it is suggested that some people have an anticipatory cortisol response to the stressor. ${ }^{25}$ In addition, if studies included in this meta-analysis collected saliva cortisol on two time points before competition, ${ }^{48}$ the time point closer to the start of the competition resulted in the highest cortisol effect size. Therefore, if studies want to examine the role of the anticipatory stress response in athletes, it is important to consider collecting saliva samples as closely as practically possible to the start of the competition.

\section{Limitations and recommendations}

While the meta-analysis identified a clear anticipatory stress response, we have to acknowledge some limitations in the analysis. As the analysis focused on the differences between studies, the variability in cortisol responses within studies was not assessed. The effects sizes derived from these studies were influenced by the large variation in cortisol reactivity between participants within a study, as demonstrated through large SD. This large variation within an included effect size influenced the ability to identify significant differences in the analysis of moderating variables. Although the moderating variables should be able to explain some of this variation within studies, the combination of the variation in reactivity within studies and the number of included effect sizes affected the examination of these moderating variables. In addition, several methodological elements that could explain the variation between and within studies should be acknowledged. As all studies collected samples before real sport competition, it is likely that salivary cortisol concentration might have been affected by a warm-up and/or the consumption of food and beverages. These factors can positively skew the concentration of salivary cortisol. ${ }^{15}$

\section{CONCLUSION}

The results of this meta-analysis identify that athletes who anticipate to compete in a sport competition have a significant anticipatory salivary cortisol response. Female athletes and athletes competing at international level do not demonstrate this significant anticipatory cortisol response. However, the analysis of moderating variables did not identify significant differences within categories of moderating variables. Therefore, our findings highlight that the previously identified emotional response in anticipation to sport competition is accompanied by a distinctive physiological stress response via activation of the HPA-axis.

Acknowledgements The authors would like to thank James Lally (JL) and Herre Bijl for their support with the searches and screening of studies.

Contributors KNvP and MB were responsible for the planning and design of the analysis. KNvP was responsible for data synthesis and data analyses.
Competing interests None declared.

Provenance and peer review Not commissioned; externally peer reviewed.

Open Access This is an Open Access article distributed in accordance with the Creative Commons Attribution Non Commercial (CC BY-NC 4.0) license, which permits others to distribute, remix, adapt, build upon this work noncommercially, and license their derivative works on different terms, provided the original work is properly cited and the use is non-commercial. See: http:// creativecommons.org/licenses/by-nc/4.0/

(C) Article author(s) (or their employer(s) unless otherwise stated in the text of the article) 2017. All rights reserved. No commercial use is permitted unless otherwise expressly granted.

\section{REFERENCES}

1. Eysenck MW, Derakshan N, Santos R, et al. Anxiety and cognitive performance: attentional control theory. Emotion 2007;7:336-53.

2. Boyce WT, Ellis BJ. Biological sensitivity to context: I. An evolutionary-developmental theory of the origins and functions of stress reactivity. Dev Psychopathol 2005;17:271-301.

3. Henry JP. Biological basis of the stress response. Integr Physiol Behav Sci 1992;27:66-83.

4. Dickerson SS, Kemeny ME. Acute stressors and cortisol responses: a theoretical integration and synthesis of laboratory research. Psychol Bull 2004;130:355-91.

5. Hellhammer DH, Wüst S, Kudielka BM. Salivary cortisol as a biomarker in stress research. Psychoneuroendocrinology 2009;34:163-71.

6. Kirschbaum C, Hellhammer DH. Salivary cortisol in psychoneuroendocrine research: recent developments and applications. Psychoneuroendocrinology 1994;19:313-33.

7. Craft LL, Magyar TM, Becker BJ, et al. The Relationship between the Competitive State Anxiety Inventory-2 and Sport Performance: A Meta-Analysis. Journal of Sport and Exercise Psychology 2003;25:44-65

8. Hayes LD, Grace FM, Baker JS, et al. Exercise-induced responses in salivary testosterone, cortisol, and their ratios in men: a metaanalysis. Sports Med 2015;45:713-26.

9. Hare OA, Wetherell MA, Smith MA. State anxiety and cortisol reactivity to skydiving in novice versus experienced skydivers. Physiol Behav 2013;118:40-4.

10. Meyer VJ, Lee $Y$, Böttger $C$, et al. Experience, cortisol reactivity, and the coordination of emotional responses to skydiving. Front Hum Neurosci 2015;9.

11. Bishop S, Duncan J, Brett M, et al. Prefrontal cortical function and anxiety: controlling attention to threat-related stimuli. Nat Neurosci 2004;7:184-8.

12. Dedovic K, Duchesne A, Andrews J, et al. The brain and the stress axis: the neural correlates of cortisol regulation in response to stress. Neuroimage 2009;47:864-71.

13. Taylor VA, Ellenbogen MA, Washburn D, et al. The effects of glucocorticoids on the inhibition of emotional information: A doseresponse study. Biol Psychol 2011:86:17-25.

14. Shields GS, Bonner JC, Moons WG. Does cortisol influence core executive functions? A meta-analysis of acute cortisol administration effects on working memory, inhibition, and set-shifting. Psychoneuroendocrinology 2015;58:91-103.

15. Kudielka BM, Hellhammer DH, Wüst $\mathrm{S}$. Why do we respond so differently? Reviewing determinants of human salivary cortiso responses to challenge. Psychoneuroendocrinology 2009;34:2-18.

16. Kirschbaum C, Wüst S, Hellhammer D. Consistent sex differences in cortisol responses to psychological stress. Psychosom Med 1992:54:648-57.

17. van Stegeren AH, Wolf OT, Kindt M. Salivary alpha amylase and cortisol responses to different stress tasks: impact of sex. Int $J$ Psychophysiol 2008;69:33-40.

18. Kudielka BM, Kirschbaum C. Sex differences in HPA axis responses to stress: a review. Biol Psychol 2005;69:113-32.

19. Kivlighan KT, Granger DA, Booth A. Gender differences in testosterone and cortisol response to competition. Psychoneuroendocrinology 2005;30:58-71.

20. Salvador A. Coping with competitive situations in humans. Neurosci Biobehav Rev 2005;29:195-205.

21. Wüst S, Federenko IS, van Rossum EF, et al. Habituation of cortisol responses to repeated psychosocial stress-further characterization and impact of genetic factors. Psychoneuroendocrinology 2005;30:199-211. 
22. Deinzer R, Kirschbaum C, Gresele C, et al. Adrenocortical responses to repeated parachute jumping and subsequent $\mathrm{h}-\mathrm{CRH}$ challenge in inexperienced healthy subjects. Physiol Behav 1997;61:507-11.

23. Brooks GA, Fahey TD, White TP. Exercise physiology: Human bioenergetics and its applications. : Mayfield publishing company 1996.

24. Jacks DE, Sowash J, Anning J, et al. Effect of exercise at three exercise intensities on salivary cortisol. $J$ Strength Cond Res 2002;16:286-9.

25. Engert V, Efanov SI, Duchesne A, et al. Differentiating anticipatory from reactive cortisol responses to psychosocial stress. Psychoneuroendocrinology 2013;38:1328-37.

26. Moher D, Liberati A, Tetzlaff J, et al. Preferred reporting items for systematic reviews and meta-analyses: the PRISMA statement PLoS Med 2009;6:e1000097.

27. Tsafnat G, Glasziou P, Choong MK, et al. Systematic review automation technologies. Syst Rev 20143:74.

28. Silva V, Carvalho A, Grande AJ, et al. Can data extraction from figures perform a meta-analysis. Cochrane Database Syst Rev 2012.

29. Carré J, Muir C, Belanger J, et al. Pre-competition hormonal and psychological levels of elite hockey players: relationship to the "home advantage". Physiol Behav 2006;89:392-8.

30. Cunniffe B, Morgan KA, Baker JS, et al. Home Versus Away Competition: Effect on Psychophysiological Variables in Elite Rugby Union. Int J Sports Physiol Perform 2015;10:687-94.

31. Filaire $E$, Maso $F$, Sagnol M, et al. Anxiety, hormonal responses, and coping during a judo competition. Aggress Behav 2001;27:55-63.

32. Borenstein M, Hedges LV, Higgins JP, et al. Introduction to MetaAnalysis. John Wiley \& Sons, 2011.

33. Bateup HS, Booth A, Shirtcliff EA, et al. Testosterone, cortisol, and women's competition. Evolution and Human Behavior 2002;23:181-92.

34. Edwards DA, Kurlander LS. Women's intercollegiate volleyball and tennis: effects of warm-up, competition, and practice on saliva levels of cortisol and testosterone. Horm Behav 2010;58:606-13.

35. Thatcher J, Thatcher R, Dorling D. Gender differences in the precompetition temporal patterning of anxiety and hormonal responses, Journal of Sports Medicine and Physical Fitness;. Turin 2004;44:300-8.

36. Hanton S, Thomas $\mathrm{O}$, Maynard I. Competitive anxiety responses in the week leading up to competition: the role of intensity, direction and frequency dimensions. Psychol Sport Exerc 2004;5:169-81.

37. Schwabe L, Oitzl MS, Richter S, et al. Modulation of spatial and stimulus-response learning strategies by exogenous cortisol in healthy young women. Psychoneuroendocrinology 2009;34:358-66.

38. Putman P, Berling S. Cortisol acutely reduces selective attention for erotic words in healthy young men. Psychoneuroendocrinology 2011;36:1407-17.

39. Uhart M, Chong RY, Oswald L, et al. Gender differences in hypothalamic-pituitary-adrenal (HPA) axis reactivity. Psychoneuroendocrinology 2006;31:642-52.

40. Stroud LR, Salovey P, Epel ES. Sex differences in stress responses: social rejection versus achievement stress. Biol Psychiatry 2002;52:318-27.

41. Iellamo F, Pigozzi F, Parisi A, et al. The stress of competition dissociates neural and cortisol homeostasis in elite athletes, Journal of Sports Medicine and Physical Fitness; . Turin 2003;43:539-45.

42. Woodman $T$, Hardy $L$. The relative impact of cognitive anxiety and self-confidence upon sport performance: a meta-analysis. J Sports Sci 2003;21:443-57.

43. Terry PC, Cox JA, Lane AM, et al. Measures of anxiety among tennis players in singles and doubles matches. Percept Mot Skills 1996;83:595-603.

44. Kirschbaum C, Klauer T, Filipp SH, et al. Sex-specific effects of social support on cortisol and subjective responses to acute psychological stress. Psychosom Med 1995;57:23-31.
45. Mellalieu SD, Hanton S, O'Brien M. Intensity and direction of competitive anxiety as a function of sport type and experience. Scand J Med Sci Sports 2004;14:326-34.

46. Hucklebridge $F$, Clow $A$, Evans $P$. The relationship between salivary secretory immunoglobulin $A$ and cortisol: neuroendocrine response to awakening and the diurnal cycle. Int J Psychophysiol 1998;31:69-76.

47. Doan BK, Newton RU, Kraemer WJ, et al. Salivary cortisol, testosterone, and $\mathrm{T} / \mathrm{C}$ ratio responses during a 36-hole golf competition. Int J Sports Med 2007;28:470-9.

48. Balthazar $\mathrm{CH}$, Garcia MC, Spadari-Bratfisch RC. Salivary concentrations of cortisol and testosterone and prediction of performance in a professional triathlon competition. Stress 2012;15:495-502.

49. Alix-Sy D, Le Scanff C, Filaire E. Psychophysiological responses in the pre-competition period in elite soccer players. J Sports Sci Med 2008;7:446-54.

50. Booth A, Shelley G, Mazur A, et al. Testosterone, and winning and losing in human competition. Horm Behav 1989;23:556-71.

51. Coelho RW, Keller B. da Silva, Andressa Melina Becker. Effect of Pre- and Postcompetition Emotional State on Salivary Cortisol in Top-Ranking Wrestlers. Perceptual and Motor Skills 2010;111:81-6.

52. Harris B, Cook NJ, Walker RF, et al. Salivary steroids and psychometric parameters in male marathon runners. Br J Sports Med 1989;23:89-93

53. Díaz MM, Bocanegra OL, Teixeira RR, et al. The relationship between the cortisol awakening response, mood states, and performance. J Strength Cond Res 2013;27:1340-8.

54. Elloumi M, Ben Ounis O, Tabka Z, et al. Psychoendocrine and physical performance responses in male Tunisian rugby players during an international competitive season. Aggress Behav 2008;34:623-32

55. Filaire E, Bonis J, Lac G. Relationships between physiological and psychological stress and salivary immunoglobulin A among young female gymnasts. Percept Mot Skills 2004;99:605-17.

56. Haneishi K, Fry AC, Moore CA, et al. Cortisol and stress responses during a game and practice in female collegiate soccer players. $J$ Strength Cond Res 2007;21:583-8.

57. McKay JM, Selig SE, Carlson JS, et al. Psychophysiological stress in elite golfers during practice and competition. Aust J Sci Med Sport 1997;29:55-61.

58. McLellan CP, Lovell DI, Gass GC. Biochemical and endocrine responses to impact and collision during elite Rugby League match play. J Strength Cond Res 2011;25:1553-62.

59. Moreira A, Bacurau R, Napimoga M, et al. Salivary il-21 and iga responses to a competitive match in elite basketball players. Biol Sport 2013;30:243-7.

60. Oliveira T, Gouveia MJ, Oliveira RF. Testosterone responsiveness to winning and losing experiences in female soccer players. Psychoneuroendocrinology 2009;34:1056-64.

61. Piacentini MF, Minganti C, Ferragina A, et al. Stress related changes during a half marathon in master endurance athletes. J Sports Med Phys Fitness 2015;55:329-36.

62. Robazza C, Gallina S, D'Amico MA, et al. Relationship between biological markers and psychological states in elite basketbal players across a competitive season. Psychol Sport Exerc 2012;13:509-17.

63. Salvador A, Suay F, González-Bono E, et al. Anticipatory cortisol, testosterone and psychological responses to judo competition in young men. Psychoneuroendocrinology 2003;28:364-75.

64. Sperlich B, Achtzehn S, Buhr M, et al. Salivary cortisol, heart rate, and blood lactate responses during elite downhill mountain bike racing. Int J Sports Physiol Perform 2012;7:47-52.

65. Yuan $Y$, Cheng P. The Use of Salivary Cortisol for Measuring Stress Experienced by Athletes in the Laboratory and Field Settings. Sport and Exercise Psychology Research Advances 2008:235-49. 